\title{
FIDES II: creyentes y no creyentes compartiendo una misma misión
}

\section{Josep Miralles Massanés'}

Palabras clave: espíritu, interioridad, antropología, calidad humana, ética, fe.

Key words: spirit, inner cultivation, anthropology, humanity, ethics, faith.

\section{Introducción: el problema}

Xavier Etxeberría ha dibujado en su ponencia un "mapa" detallado de la problemática de la "fides" en los centros de UNIJES. Esta ponencia pretende complementar la de Xavier Etxeberría y focalizar la atención en un hecho que muchas veces se ha visto como amenaza para la formación humana y creyente en un centro educativo, pero que ahora empezamos a comprender como una oportunidad: se trata del pluralismo de opciones vitales de vida en nuestros centros universitarios. Este pluralismo se da en el profesorado, en los alumnos y en el personal de administración y servicios (PAS). Es un pluralismo que es más complejo de lo que a primera vista parece. Porque no sólo comparten el mismo proyecto de formación creyentes y no creyentes, ni sólo creyentes de diversas religiones. Entre los creyentes hay un gran pluralismo: los hay que apenas han asimilado el Vaticano Il y los hay que suspiran por un Vaticano III que afronte con decisión y valentía los desencuentros entre la Iglesia y el mundo contemporáneo. Los hay convencidos de la bondad de su fe y

1 Facultad de Ciencias Empresariales - ESADE, Universidad Ramon Llull, Barcelona. Texto revisado recibido el 2 de noviembre de 2008. 
los hay que la viven con dificultad por múltiples causas: la experiencia personal del mal que contradice la idea de un Dios bueno y omnipotente; la experiencia de una Iglesia que parece demasiado lejana de lo que fue y vivió Jesús de Nazaret, etc. Entre los no creyentes también hay diversas aproximaciones vitales: indiferentes al hecho religioso; en búsqueda existencial de sentido; comprometidos con la transformación del mundo o serenamente instalados en la vida profesional y privada.

Para los centros universitarios vinculados a la Compañía de Jesús, la cuestión es si esta diversidad de situaciones y aproximaciones resulta un impedimento a la hora de ofrecer a los alumnos, y al mismo personal de los centros, un camino de progreso en la línea de la utilitas, la iustitia, la humanitas y la fides. El pluralismo, para ser vivido sin conflicto, puede llevar a una tolerancia que en la práctica signifique el silencio y la homogeneización a la baja: o no se habla de ello o se habla sólo del "mínimo" en el que podemos estar de acuerdo. Este tipo de planteamiento y de problema afecta a todos los valores pero de una manera especial a la fides, precisamente por la voluntad, que todos compartimos, de ser máximamente respetuoso en este terreno.

El problema se acentúa en el contexto actual de desprestigio de la institución eclesial y de privatización de la fe. Ambas situaciones desembocan en un discurso público que evita referirse a la fe. En esta situación es difícil para todos plantear la cuestión de la fe como una pregunta relevante para la sociedad y para las personas. En la práctica, muchas personas pasan muchos años sin compartir sus convicciones profundas ni con los compañeros de trabajo ni con los amigos.

Pues bien: de lo que se trata es de afrontar esta situación y de ofrecer un planteamiento de la misma que permita potenciar el dinamismo y las capacidades de cada persona, esté vitalmente donde esté, para que cada uno pueda progresar personalmente y pueda ayudar a los demás en la común misión de formar personas.

Dicho de otro modo: si no se profundiza en lo que significa fides y "no creencia" podríamos llegar a una "división del trabajo" demasiado simplificada: los creyentes cultivan y ayudan a cultivar las cuatro dimensiones (utilitas, iustitia, humanitas, fides), los no creyentes cultivan y ayudan a cultivar las tres primeras. Llegar a esto significa ya un gran éxito histórico, superados antiguos antagonismos, pero podemos llegar mucho más lejos porque tanto la fe como la no fe, bien entendidas, son situaciones dinámicas y relacionales: el propio progreso depende siempre de una buena relación con los que son diferentes y nos aportan su diferencia a la vez que reciben la nuestra. 
Para avanzar en este camino se pueden seguir dos caminos. Para algunos, la ética ofrece la base de un acuerdo, porque la ética se basa en la razón que todos, creyentes y no creyentes, compartimos. Otros pensamos que hay que ir más allá de lo que habitualmente se entiende por ética proponiendo una antropología que, a la vez que fundamenta la ética, descubra la dimensión espiritual del ser humano. Nosotros nos inclinamos decididamente por la segunda opción. Por ello, mostraremos, en primer lugar, los inconvenientes de la "vía ética", para desarrollar, en segundo lugar, esta antropología a la que aludíamos: una antropología que permita a creyentes y no creyentes colaborar codo a codo no sólo desde la tolerancia sino desde un respeto mutuo real y profundo.

\section{La insuficiencia de la ética}

En el contexto de la educación universitaria muchos piensan que la ética proporciona una base compartida y suficiente para sustentar la misión común. Dos argumentos servirían para justificar esta posición. En primer lugar, la ética, basada en la razón humana, que se supone universal, permite superar la particularidad de la confesión religiosa sólo aceptada por un sector minoritario. En segundo lugar si, como algunos han dicho, la realidad de la fe no fuera una cuestión de ortodoxia teórica sino sobre todo, de amor al próiimo, solidaridad y compromiso con los demás, podría parecer que la ética es suficiente para sustentar la misión común de formar personas ${ }^{2}$. Existen, sin embargo, argumentos contra esta posición y no es tan claro que la ética pueda proporcionar una base común para la formación integral de la persona en el contexto universitario.

En primer lugar existiría un problema de definición dado que la ética es un campo de debate enormemente plural ${ }^{3}$. En el mundo occidental existen muchas éticas,

\footnotetext{
${ }^{2}$ Mucha gente ha citado con frecuencia el título de un libro de González Ruiz, Creer es comprometerse, para expresar esta posición reduccionista de la fe. En realidad, lo que hacía Gonzalez Ruiz en su libro era expresar su preocupación por la reducción de la fe a una cuestión teórica olvidando la exigencia de que desemboque en un compromiso práctico

${ }^{3}$ En los párrafos siguientes no pretendo desarrollar un tratado de ética. Por esto hablo de "modas" en la manera de argumentar en debates y artículos que en muchos casos carecen de rigor filosófico. Sólo pretendo insinuar esquemáticamente las dificultades que suscita de hecho el lenguaje ético en las discusiones sobre el tema que nos ocupa, en una situación de pluralismo filosófico en la que, aunque la ética apele siempre a la razón, sin embargo hay un amplio debate sobre los principios fundamentales de la ética, debate que da lugar a diferentes escuelas de pensamiento. Estas escuelas de pensamiento se traslucen con frecuencia en el debate público. Pienso que las diferentes éticas remiten a diversas antropologías y por esto argumentaré después que hace falta remontarse a la antropología.
} 
cada una con su correspondiente lenguaje y argumentación: ética de virtudes, éticas utilitaristas, éticas deontológicas. Estas éticas compiten entre ellas y pronto deberán hacerlo con éticas enraizadas en tradiciones culturales distintas de la occidental. Veamos, a continuación las dificultades que presenta cada una de ellas para nuestro propósito de formar integralmente a la persona humana.

- El lenguaje de "los valores" está hoy de moda. Se dice y repite que hay "crisis de valores" y que por esto hay que "educar en valores". Pero ¿qué valores en concreto? ¿Los valores de la sociedad de consumo y del neoliberalismo: individualismo, competitividad, consumismo (de más o menos calidad)? ¿Los valores de alguna de las grandes tradiciones ideológicas: el socialismo o el liberalismo? ¿Los valores de algunas grandes tradiciones religiosas? Pero justamente, tanto las ideologías como las religiones están en crisis, no son aceptadas como ofertas universales de sentido... y además, y es lo más importante, ¿̇cómo "discernir" entre estas diferentes ofertas de sentido para elegir una de ellas, o para componer a partir de ellas un "sistema" de valores coherente y humanizador?

En realidad, este necesario "discernimiento" tiene como presupuesto una "antropología" que justifique por qué la sensibilidad en la captación de la realidad y la evaluación del impacto de nuestras acciones sobre las personas permite una decisión correcta. Creo que una antropología de este tipo subyace en el "discernimiento de espíritus" característico de la espiritualidad ignaciana.

Por otra parte: suponiendo que se sepan elegir los valores, ¿̇cómo manejar sus inevitables contradicciones? La vida no es una "armonía preestablecida" en la que siempre se puedan articular adecuadamente todos los valores implicados en una situación. Y todavía una última cuestión: ¿̇cómo proponer y trabajar los valores? Los valores no son verdades teóricas que se impongan universalmente por la lógica de su argumentación y no es suficiente conocerlos; hay que "admirarlos", dejarse seducir por ellos y trabajarlos hasta incorporarlos a las propias motivaciones, en la vida cotidiana y en las grandes decisiones.

- También está de moda el lenguaje de la responsabilidad. Por ejemplo, en el grado de Administración y Dirección de Empresas (ADE) se habla de la "Responsabilidad social de las empresas" como si esto fuera ya suficiente para orientar la actividad organizativa. Pero las dificultades vienen cuando hay que precisar de qué se es responsable, ante quién y por qué. En realidad, todas estas preguntas nos remiten al apartado anterior, a los valores que hacen que determinadas consecuencias de nuestras acciones se consideren positivas o rechazables. También depende de la jerarquía de valores determinar ante quién y por qué se es responsable: ¿̨uién 
tiene derecho a exigirnos ser responsables? ¿̇El accionista, todo "stakeholder", el compatriota, todo hombre y toda mujer, especialmente el débil y desprotegido? Y finalmente, ¿̇en nombre de qué somos responsables? ¿por compartir la ciudadanía nacional, por compartir la condición humana, por ser todos hijos de Dios? Otra vez, todos estos interrogantes hacen necesaria una antropología que ponga de manifiesto que las personas somos algo más que "individuos" aislados: los seres humanos nos definimos a nosotros mismos por la manera en que nos descubrimos en relación con los demás y por la manera de establecer relaciones con ellos, dicho de otra manera, al establecer a quién le damos el derecho de interpelarnos sobre la responsabilidad de nuestros actos.

- Finalmente existe el lenguaje de los derechos y deberes, del que ya se ha hecho mención en el párrafo anterior. Es el lenguaje universal de los derechos humanos y de los deberes absolutos ("imperativos categóricos", como decía Kant). Es un lenguaje fuerte, pero abstracto y la sensibilidad postmoderna lo ha debilitado fuertemente al acentuar hasta la exageración el individualismo, el relativismo y la importancia de la sensibilidad. En este lenguaje "deontológico" aparecen los problemas radicales de la ética en cuanto vía de transformación de la persona. En primer lugar, el conocimiento del bien, siendo importante, no garantiza que llegue a realizarse porque el peligro de la incoherencia entre las palabras y los hechos acecha siempre al ser humano. En segundo lugar, en la ética deontológica brilla de manera especial su apelación a la razón como base de su universalismo cosmopolita; pero este brillo necesita de una sensibilidad educada y de unos valores interiorizados para poder ser percibido de manera que mueva a la acción.

Detrás de cada una de estas éticas se encuentra una antropología distinta, cada una con sus dificultades ${ }^{4}$. Frente a ellas, propongo una antropología aceptable para creyentes y no creyentes que guíe a la ética en su búsqueda de la acción buena pero que apunte más allá: a desarrollar una auténtica calidad humana, para llegar a ser bueno como el árbol bueno que produce buenos frutos, según

${ }^{4}$ Mi posición respecto a estas éticas y antropologías responde a lo que J. Ferrater Mora llamó "integracionismo" y que se expresa bien en este párrafo:

Dadas dos posiciones en conflicto [...] cada posición puede considerarse como una posición límite, rotu lable mediante uno o más conceptos-límite; las insuficiencias de una posición son corregibles mediante el paso a la posición opuesta, que entonces funciona como complementaria [...] Desde este punto de vista, la posición que defiendo puede llamarse integracionismo. El integracionismo, sin embargo es un método, no una concepción de la realidad (J. FerRATER MORA (1979), De la materia a la razón, Madrid, Alianza).

Este no es el lugar de exponer como relaciono estas éticas, según este método. En todo esto sigo el pensamiento de mi compañero de ESADE, J. M. LozANo, Ética y empresa, Madrid, Trotta, 1999. 
la conocida parábola evangélica. Y para llegar a esta calidad humana hay que descubrir que el progreso en este campo no se realiza sólo por el propio esfuerzo más o menos voluntarista. Hay que descubrir que lo más esencial de la vida es fundamentalmente don y regalo, que hay que saber descubrir, recibir y agradecer. Todo esto va más allá de lo que habitualmente se entiende por ética; esto es trabajar el "espíritu humano", trabajo que consiste principalmente en educar la capacidad de reconocer y asumir este don capaz de transformar la propia vida.

Esta antropología está estructuralmente abierta a la posibilidad de la fides y también de la no creencia y, a la vez, es capaz de potenciar y educar la utilitas, la iustitia y la humanitas. Esta misma antropología muestra que la cuestión del sentido de la vida es una cuestión inevitable para el ser humano y a la vez que su respuesta no es nunca (ni en el creyente ni en el no creyente) la tranquila posesión de una verdad dominada. Por ello mismo esta antropología permite el diálogo enriquecedor entre una y otra opción vital.

Para situar de entrada el enfoque de este análisis puede ser útil el esquema siguiente. Vamos a focalizarnos en la zona del "espíritu humano" ("eh", con minúsculas): lo que da al ser humano su específica peculiaridad; la fuente de la humanidad, la justicia y la profesionalidad, la posible apertura a la trascendencia, el motor del dinamismo humano siempre en movimiento.

\section{Figura I}

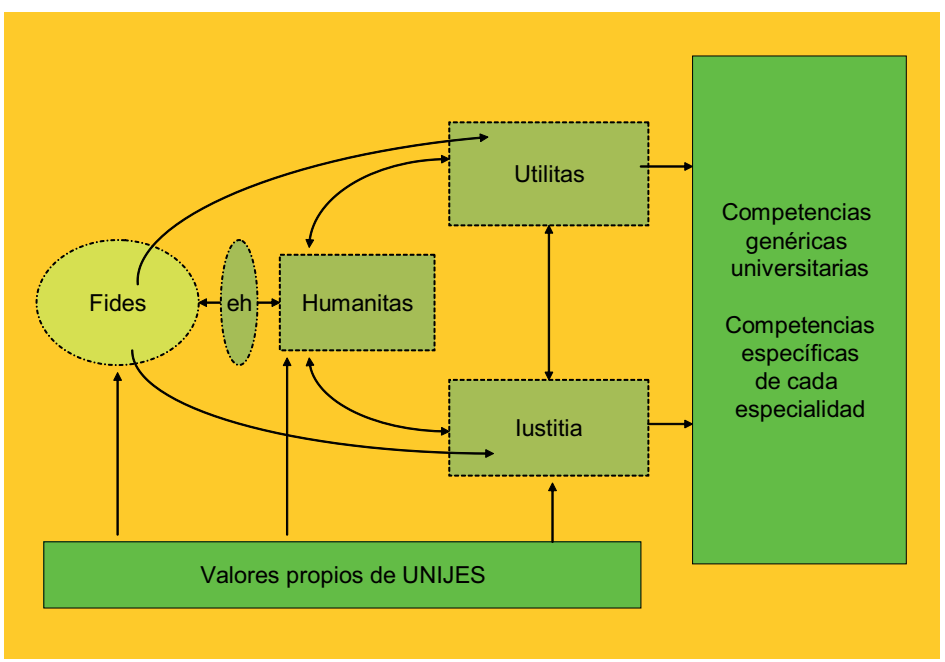


El esquema pretende visualizar la relación existente entre competencias exigidas por el Espacio Europeo de Educación Superior (EEES), y los valores (o metacompetencias) propuestas por UNIJES siguiendo el modelo Ledesma-Kolvenbach. Las competencias EEES pueden interpretarse solamente en función de las exigencias del mercado, pero adquieren una nueva significación a la luz de los valores propuestos por UNIJES. La utilitas y la iustitia influyen directamente en la manera de interpretar las competencias EEES. La humanitas se sitúa como trasfondo de ambas. La fides se sitúa en otro nivel más fundamental y de otro orden. El espiritu humano (eh) aparece como "lugar" o más bien "estructura" que, siendo el núclo fundamental de la humanitas, puede abrirse a la fides. Las flechas relacionan cada recuadro con todos los restantes porque el desarrollo o la atrofia de cada valor UNIJES influyen en todos los demás. Los recuadros tienen línea discontinua para expresar la "porosidad" de cada valor al conjunto de la realidad (que para el creyente está llena del Espíritu, con mayúscula esta vez: el Espíritu de Dios) $)^{5}$.

\section{Antropología}

Lo raro es vivir (Carmen Martín Gaite).

Este curioso título de una novela de Carmen Martín Gaite revela la extraña capacidad del ser humano de "admirarse ante la vida": no sólo hay cosas que nos parecen "raras", sino que el conjunto de la vida nos parece (al menos en ciertas situaciones vitales) "raro", sorprendente, no-obvio: podríamos no existir y esto nos produce extrañeza y, a veces, admiración.

\section{I. La peculiaridad del ser humano}

Esta "rareza" de la vida se vive especialmente en muchos momentos en que el ser humano se pregunta por la "razón" o el "sentido" del vivir ${ }^{6}$. Porque el ser

\footnotetext{
${ }^{5}$ El texto quiere mostrar el punto de vista del creyente de una manera que el no creyente pueda también aceptar. El creyente cree que todo ser humano se encuentra con Dios y le da una respuesta a través de la opción fundamental de su vida. Evidentemente, el no creyente no interpreta de la misma manera su propia existencia ni la del creyente, pero puede entender que el creyente vea la vida de otro modo.

${ }^{6}$ Los párrafos que siguen se inspiran y a veces citan literalmente a J. MARTíN VELASCO (2000) El hombre y la religión, Madrid, PPC, cap. V "Religión y sentido de la vida en las sociedades postreligiosas", p.s $143-160$
} 
humano no vive simplemente como vive un animal: se pregunta si puede vivir "mejor", si lo que hace tiene "sentido". En circunstancias extremas se puede plantear que vale la pena sacrificar el hecho de vivir por una causa que se ve como "más importante que la vida". Porque sentimos que si no obráramos así perderíamos aquello que da sentido a nuestro vivir. No queremos perder la razón de ser, el sentido de la vida: no queremos "propter vitam, vitae perdere causas" ("por causa de la supervivencia -entendida sólo como supervivencia- perder la razón de ser de la vida").

Esta "distancia" entre lo que la vida es y lo que queremos que sea, entre lo que es y el sentido de este "ser", ha sido y es objeto de indagación universal. La gran literatura de todos los siglos ha vuelto una y otra vez sobre este tema: la tragedia griega expresa la admiración y el horror ante el destino fatal (¿inmerecido?) del ser humano; Antígona reivindica por primera vez en la historia occidental la primacía de la conciencia y de una ley no escrita universal por encima de las leyes de la ciudad y por ello pierde la vida. Esta literatura a veces es creyente (Dostoyevsky, Tagore) a veces es atea o agnóstica: Camus, Yourcenar ("Memorias de Adriano"), Koetzee.... Esta indagación universal, en el tiempo y en el espacio, tiene un terreno común: la pregunta por el sentido de la vida humana. Una pregunta muy especial, porque ninguna respuesta madura puede pretender ni acabar con la pregunta ni imponer a otros la propia respuesta como si fuera una verdad universal y adquirida.

La pregunta por el sentido de la vida está íntimamente conectada con las religiones y con el Misterio al que todas ellas remiten. Para algunos, creyentes y no creyentes, el hecho mismo de plantearse esta pregunta es ya, en cierta manera, "religión". Paul Tillich, teólogo protestante decía: Ser religioso significa plantearse apasionadamente el sentido de la vida y estar abiertos a las respuestas que incluso pueden llenarnos de estremecimiento. Ortega, un filósofo no creyente decía a su vez: Todo hombre que piense: "la vida es una cosa seria", es un hombre intimamente religioso.

Personalmente, pienso que es mejor respetar la definición que cada uno hace de sí mismo y no imponer (ni siquiera proponer) una etiqueta de "creyente" o "religioso" a quien no se considera de este modo. Pero sí creo interesante plantearse si esta pregunta se enraíza en algo esencial al ser humano ly por lo tanto "imprescindible") o en una "cualidad" que sólo algunos tendrían y que sería por lo tanto "prescindible". J. Martín Velasco afirma claramente la existencia de un sustrato antropológico de la religión que él identifica en la coexistencia en el ser 
humano de dos dimensiones: su ineludible finitud y la superación de esta finitud que supone el mismo hecho de percibirla ${ }^{7}$.

\subsection{El lenguaje y la doble perspectiva sobre la realidad}

A lo largo de la historia se han dado distintos nombres a esta manera de ser del ser humano. Se ha hablado del "alma", del "espíritu", sea como una "parte" del ser humano, sea como algo que lo forma o configura por entero. Las distintas culturas le han asignado un "lugar" o una "sede" en el cuerpo humano: el corazón, el vientre, los riñones, el cerebro ${ }^{8}$.

En una cultura postmetafísica como la nuestra tal vez sea más inteligible para la mayoría caer en la cuenta de que el hecho aparentemente sencillo de ser "seres hablantes" abre la posibilidad de todo este tipo de interrogantes e indagaciones?

Los animales no hablan. Su "mundo significativo" lo constituye el conjunto de estímulos al que son sensibles debido a su programación genética. El mundo de un animal es un mundo de estímulos cuya única realidad es la de ser interpeladores para el sujeto animal, despertando las reacciones programadas genéticamente que están orientadas a la supervivencia.

En cambio, el ser humano es un ser que habla. Y el lenguaje introduce un salto cualitativo y decisivo en la manera de relacionarse con su entorno. M. Corbí lo formula así:

Gracias a la mediación de la lengua podemos distinguir entre lo que es el significado de las realidades para nosotros como vivientes [que buscamos primariamente la supervivencia] y lo que las cosas son en si mismas.

Como consecuencia de esta estructura del lenguaje se produce una doble experiencia de la realidad: una configurada en función de nuestras necesidades, como sucede con los demás animales; y otra que no está en función de nuestras necesidades, no relativa a ellas...

7 Ver op. cit. pp. 149-150.

${ }^{8}$ Ver J. Meloni (2001) La mistagogía de los Ejercicios, Bilbao, Santander, Mensajero y Sal Térrea, Cap. 3 "Los elementos antropológicos de los Ejercicios" y también Lo uno en lo múltiple.

${ }^{9}$ La relación del lenguaje con la estructura antropológica del ser humano tiene especialmente en cuenta las obras de M. CORBí, En su último libro se puede encontrar una síntesis de su pensamiento: (2007) Hacia una espiritualidad laica, Barcelona, Herder. Ver cap. 2. 
La experiencia relativa de la realidad se nos muestra como estímulo para nuestra acción.... como valor de supervivencia. La experiencia absoluta de la realidad se nos presenta como ser y valor sin relación con nuestras necesidades, como separada, ab-soluta de toda relación con nosotros, como estando ahí, en si misma"10

Es decir: los seres humanos distinguimos el que algo sea significativo "para mi" del hecho de que "sea" aunque no tenga ninguna relación conmigo. Esta distancia entre lo me afecta y lo que es introduce una capacidad muy especial de relacionarse con el mundo.

Por una parte, el ser humano, debido a su base biológica, mira el mundo (y se relaciona con él) de manera "interesada": primariamente quiere sobrevivir, buscar la felicidad y el bienestar. Pero al reconocer que la "realidad" existe en si misma, adquiere una capacidad de distancia respecto al "estímulo" que le impacta, que abre el camino a la inacabable aventura del vivir humano.

Gracias a esta distancia, el ser humano se hace capaz de conocer científicamente, distanciándose metódicamente del conocimiento espontáneo "interesado", buscando cómo la realidad es (o funciona) en si misma. También se hace capaz de inventar herramientas con las que trabajar una realidad que existe y que tiene su propia lógica, es decir inventa y desarrolla la tecnología y la capacidad de trabajar la naturaleza.. Se hace capaz de captar la belleza que existe más allá de lo que le agrada instintivamente y así desarrolla su capacidad artística. También se hace capaz de pensar no sólo en lo que es sino también en lo que debiera ser y se abre a la indagación moral y al reconocimiento del valor absoluto de la dignidad humana. Se abre finalmente a la admiración ante la existencia que antes mencionábamos. Descubre que esta realidad que le circunda es sagrada: misteriosa, fascinante, tremenda (es decir, capaz de conmover la existencia) y también digna de ser amada y servida ${ }^{11}$.

Todas esta son experiencias humanas. En todas ellas el sujeto es un "animal biológico y psíquico" que quiere sobrevivir, pero en todas ellas funciona, más o menos, una capacidad de distancia enraizada en el "silencio" de interpretaciones y apegos

\footnotetext{
${ }^{10}$ M. CORBí, p. 30. Los corchetes son míos.

"La alusión a la realidad como "fascinans et tremens" alude al clásico libro de R. Oто (1980) Lo santo, Madrid, Alianza Editorial. Que la realidad es digna de ser amada y servida alude a la "Contemplación para alcanzar amor" de los Ejercicios de S. Ignacio [233], aunque allí, Ignacio habla de Dios y no de la realidad. Creemos que también se puede decir que la realidad, creada por Dios es digna de amor y servicio.
} 
que se caracteriza por la "gratuidad": el ser humano puede interesarse por la realidad con (paradójicamente) un altísimo grado de "des-interés" respecto a su propia vida biológica y psíquica, des-interés que se expresa en un gran respeto, admiración y amor por la Naturaleza, por los demás y también por si mismo y, por Dios (si se le da este nombre a la Realidad última) ${ }^{12}$.

\subsection{El espíritu y el Espíritu}

Esta peculiar manera de ser del ser humano es lo que llamamos su dimensión espiritual. Se trata de la misma estructura del ser humano. Pero se trata de una estructura "reflexiva" porque el ser humano cobra conciencia de ella en lo que llamamos su interioridad.

La dimensión espiritual del ser humano es el "lugar" de la opción creyente y también de la opción por la no creencia. Ninguna de las dos es demostrable con una racionalidad formal que pueda ser universal. Ambas son vividas como resultado de una opción libre y razonable ${ }^{13}$ a la vez que no puede imponerse a los demás.

La experiencia religiosa es la captación de la realidad última como Misterio y a su vez del Misterio "como bien"14, como salvación, como liberación, que puede tomar múltiples formas según las diferentes tradiciones religiosas, a su vez enraizadas en diferentes culturas. Siempre es una experiencia transformadora orientada al silencio del ego (frente al egocentrismo), al amor (frente a la posesión), a la apertura a los demás y al Otro, sea al Dios personal de las religiones monoteístas, sea al Vacío que es Plenitud, propio de las religiones "oceánicas" orientales.

\footnotetext{
${ }^{12}$ Al hablar de la experiencia religiosa creo que deberíamos asumir lo que R. Paniker ha llamado la intuición "cosmoteándrica": no separar sino integrar la experiencia de la relación con la Naturaleza, con los otros seres humanos y con Dios.

${ }^{13}$ En contextos económicos y políticos (que son los de nuestras facultades de empresariales) lo racional alude con frecuencia a la lógica medios-fines, la lógica del interés propio, lo que la filosofía de la Escuela de Frankfurt criticó como "racionalidad instrumental". Lo razonable es aquello que puede ser entendido y aceptado por otro ser racional pero ello no implica que todos deban sacar la misma conclusión. Este es el caso en muchas discusiones de índole moral y política: cada uno puede entender y respetar los argumentos del otro pero ello no lleva a la unidad de criterios sino a un pluralismo "razonable". Sobre esta distinción entre racional y razonable, cf. J. RAwLS (2000) La justicia como equidad, Barcelona, Paidós, pp. 27 y 127.

14 J. Martín Velasco, El hombre y la religión, p. 151
}

Revista de Fomento Social 63 (2008) 
Como el ser humano es un animal hablante que necesita comunicar lo que vive y decírselo a si mismo, la experiencia religiosa ha sido descrita una y otra vez mostrando sus múltiples formas. Sin embargo, el sujeto religioso reconoce siempre que se experimenta como formando parte de un Misterio que le sobrepasa y que nunca puede expresar adecuadamente.

Por esto la experiencia religiosa es apertura progresiva a la Realidad "cosmoteándrica" vivida como "Espíritu" (esta vez con mayúsculas, para expresar su sentido trascendente), apertura que se vive como "búsqueda" de Dios. Una búsqueda que tiene tantas dimensiones como facetas tiene el ser humano. Buscamos a Dios en la acción discerniendo cuál es su "voluntad". Le buscamos en nuestro ser acogiendo su capacidad transformadora, que nos hace capaces de amar cada vez más des-interesadamente, con mayor gratuidad. Buscamos la experiencia de Dios en nuestra interioridad, en la oración que es deseo y es contemplación, y que a su vez revierten en la búsqueda de Dios en la acción (ser "contemplativo en la acción" como decía el P. Nadal de S. Ignacio y de los jesuitas).

\subsection{El espíritu y la no creencia}

La estructura espiritual del ser humano es también el "lugar" de la no creencia, de la opción por el sentido de la vida sin trascendencia o divinidad.

Esta opción por el sentido es perfectamente razonable. Las dificultades intelectuales y prácticas para la fe en Dios son suficientemente fuertes como para hacer comprensible y razonable su negación, aunque dejan a su vez un resquicio suficientemente grande para que la fe sea a su vez razonable.

La no creencia desarrolla muchas formas pero aquí nos interesan especialmente las que asumen con lucidez y vigor la cuestión del sentido último de la vida. La opción no creyente consiste fundamentalmente en la aceptación lúcida de que la aspiración inherente al ser humano de un sentido último de la vida no tiene por qué resolverse de una vez por todas con la aceptación de un Dios benevolente. Y también forma parte de la opción del no creyente lúcido la experiencia de la validez incuestionable de ciertos valores que podríamos llamar "humanamente últimos" como la libertad, la dignidad humana, el derecho al respeto de esta dignidad y, finalmente, el amor. Son valores "últimos" y en cierto modo "absolutos" pero lo son "para el hombre" con lo que ello comporta de limitación y relatividad. 
La grandeza del no creyente consiste en mantener los dos polos de la realidad tal como él la percibe: la realidad y su misterio no son percibidos "como bien", pero a la vez, se afirma el valor y la dignidad del ser humano.

Desde esta perspectiva hay que relativizar la crítica que antes se ha hecho de la ética porque, en la práctica, en muchos casos, la ética incluye, aunque sea implícitamente, el reconocimiento de la dimensión espiritual del ser humano y supone una opción consciente y comprometida por una humanidad más libre, justa, respetuosa y solidaria.

Quisiera subrayar dos itinerarios que me parecen especialmente interesantes en la relación entre creyentes y no creyentes, itinerarios que se pueden ejemplificar con dos nombres propios (simplificando mucho la posición de cada uno de ellos).

El primero de ellos es A. Camus. No soy un experto en su obra pero he de decir que siendo muy joven quedé seducido por la lucidez y el amor al hombre que se expresan en La peste. El cuadro que compone con las diferentes actitudes ante la peste y las exigencias de solidaridad que comporta la lucha contra ella muestra su tremenda lucidez: los hombres no somos siempre buenos ni damos la talla que sería exigible. En muchos casos, comportamientos objetivamente correctos se apoyan en legitimaciones muy discutibles (en el caso del jesuita Paneloux). Taroux, el "santo laico" que encarna la lucha contra la peste acaba muriendo... Y, sin embargo, el doctor Rieux reconoce que en los hombres hay más cosas dignas de admiración que de desprecio. La reflexión del Dr. Rieux acaba diciendo:

Pero sabía que, sin embargo, esta crónica no puede ser el relato de una victoria definitiva. No puede ser más que el testimonio de lo que fue necesario hacer y que sin duda deberían seguir haciendo contra el terror y su arma infatigable, a pesar de sus desgarramientos personales, todos los hombres que, no pudiendo ser santos, se niegan a admitir las plagas y se esfuerzan, no obstante, en ser médicos.

La reflexión de Camus es desgarrada, carente de esperanza definitiva pero capaz de un amor desinteresado y radicalmente comprometido con el ser humano víctima del mal simbolizado por la peste, cualquiera que sea este mal: enfermedad, opresión, explotación, etc.

Muy distinta de tono es la reflexión de Compte-Sponville ${ }^{15}$, autor de un libro reciente, sereno y optimista, tal vez demasiado lejano del sufrimiento humano,

${ }^{15}$ A. Compte-Sponville (2006) El alma del ateísmo, Barcelona, Paidós. 
pero que expresa bien algo que hoy día hemos de considerar: la posibilidad de un misticismo laico.

Compte-Sponville reivindica una "espiritualidad sin Dios". Esto implica el reconocimiento de la dimensión espiritual del ser humano:

"El espíritu no es una sustancia, sino una función, una potencia, un acto (el acto de pensar, de querer, de imaginar, de bromear) y al menos este acto es indudable porque cualquier refutación lo supone" (p. 144)... Somos seres finitos abiertos al infinito... seres relativos abiertos al absoluto. Esta apertura es el espíritu mismo. La metafísica consiste en pensarla; la espiritualidad, en experimentarla, ejercerla, vivirla" (p. 145)

Esta experiencia puede llegar más lejos de lo que habitualmente se piensa: el autor narra con gran belleza y convencimiento su experiencia mística y a la vez atea del ser, de la realidad: una experiencia pacificadora, lúcida, gratuita, que tiene innegables ecos de las religiones oceánicas caracterizadas más por la iluminación que por la salvación:

"Ya no había palabras, ni carencia, ni espera: puro presente de la presencia...Ya no había ego, ni separación ni representación: únicamente la presencia silenciosa de todo. Ya no había juicios de valor: tan sólo lo real. Ya no había tiempo: tan sólo el presente. Ya no había la nada: tan sólo el ser. Ya no había insatisfacción, ni odio, ni miedo, ni cólera ni angustia: únicamente alegría y paz" (p.164-165)

Lo interesante del libro de Compte-Sponville es su permeabilidad a la sensibilidad actual que incluye la pluralidad de experiencias en el debate sobre el sentido último de la vida. También lo es la decidida aceptación del término espiritualidad, incluso en un contexto ateo o agnóstico, como un elemento necesario de un desarrollo personal que no mutile ninguna dimensión del ser humano. En cambio parece muy alejado del dramatismo de la vida humana y del sufrimiento solidario con las víctimas de la injusticia.

La consideración de las dos opciones vitales caracterizadas por la fe y por la no creencia muestra algo importante: su carácter dinámico; su carácter de "vías" por las que se apuesta y por ello mismo se transita, de tal modo que el caminar refuerza la opción y, a la vez y paradójicamente, la mantiene abierta a un diálogo sincero con otras opciones vitales. También muestra su carácter "motor": las dos opciones, cuando son vividas con lucidez y se alimentan en la interioridad y el compromiso práctico, se convierten en poderosos motores de transformación del conjunto de la vida que entonces se vive como una indagación y un discernimiento constante, orientado en los dos casos al desarrollo de la humanitas, la iustitia y la utilitas, y que en el caso de la opción creyente se abre, 
en la fides, no sólo a trabajar el (propio) espíritu sino a permitir que el Espíritu de Dios trabaje en uno'b.

\section{Antropología práctica y "practicable”}

Decimos que esta antropología es práctica y practicable porque permite pensar en qué consiste el desarrollo de la dimensión espiritual del ser humano y la función que tiene la interioridad en este desarrollo. A partir de aquí, es posible pensar en pedagogías que desarrollen todas estas dimensiones de la persona. Estas pedagogías pueden cubrir sólo un aspecto de la formación humana pero en realidad deben ser interpretadas como maneras de trabajar el espíritu que últimamente apuntan a definir la opción fundamental por la fe o la Increencia lúcida y que, en este sentido, repercuten sobre el conjunto de la vida.

\section{I. Una espiritualidad polémica pero necesaria}

Decía Aristóteles que todos los seres humanos buscan la felicidad como su fin último. Esta búsqueda de la felicidad forma parte de esta distancia que el ser humano establece entre lo que es y lo que debiera ser, entre lo experimenta y lo que desea. Nuestra sociedad tiende espontáneamente a llenar esta distancia entre la realidad de la vida y lo que quisiéramos que fuera, por una triple vía: la posesión, el dominio y el estatus. De esta manera nuestra sociedad se "distrae" de lo esencial.

Muchos sienten que no son todo lo que quisieran ser y buscan llenar este vacío de ser llenándolo de cosas, con un "tener" mayor. No se sienten reconocidos como desearían y buscan este reconocimiento mediante el dominio de los demás. Las situaciones que viven no les gustan y buscan "distraerse" de ellas. En todos los casos se parte de un mismo presupuesto: la felicidad consistiría en la tranquilidad de asegurar lo que consideramos necesario para la vida a partir de un "ego" que, por otra parte, es insaciable: la distancia de la que antes se ha hablado crea una brecha entre lo que es y lo que podría llegar a ser que por definición es inagotable. Por lo tanto, la vía del incremento ilimitado de la posesión, el dominio y el estatus nunca podrá conducir a la felicidad; al contrario provoca más y más insatisfacción. La "distracción" no es por tanto una buena solución ${ }^{17}$.

\footnotetext{
${ }^{16}$ Ver, por ejemplo, Rm. 7,22-27 y Gal. 5,16-26

17 J. MARTín VeLASCO debate estos puntos clara y brevemente en (1995) La experiencia cristiana de Dios,
} 
En realidad, el miedo a perder lo que consideramos "necesario" para la vida no puede vencerse "amarrando" los bienes que creemos necesitar. Sólo podemos acercarnos a la felicidad trabajando este "ego" que busca instintivamente la supervivencia y el bienestar a todos los niveles y que se deja engañar por la posesión de lo inmediato. Trabajar el ego significa "descentrarlo": experimentar que la felicidad se alcanza cuando el interés sale de uno mismo y se centra en lo "otro" (la Naturaleza, los seres humanos, Dios) ${ }^{18}$.

Decir esto es algo muy polémico. El sistema económico y cultural en el que vivimos orienta hacia el consumo y el dominio como símbolos de estatus y por lo tanto como medios de alcanzar la plenitud deseada. El consumo es también la herramienta de distracción, la que bloquea la posibilidad de plantearse las grandes cuestiones de la vida.

¿Podemos basarnos en esta antropología para educar hombres y mujeres para que consigan los medios que necesitan para desenvolverse en la vida como formulaba el P. Ledesma a fines del siglo XVI? ${ }^{19}{ }^{2}$ No los llevamos al fracaso?

Contra lo que pudiera parecer, esta antropología es sumamente útil en un momento de cambio acelerado en todos los sentidos: tecnológico, social, económico, político y cultural; en una sociedad que no puede utilizar las antiguas soluciones para los nuevos problemas; en una sociedad cuyos grandes problemas (supervivencia económica y ecológica, convivencia intercultural, gobernanza mundial) provienen precisamente de lo que en el pasado se consideraron buenas soluciones.

Esta sociedad necesita de personas y profesionales capaces de una gran libertad interior para desvincularse de las soluciones tradicionales y capaces de inventar otras nuevas. Y esta capacidad de invención ha de llegar hasta entender el ser humano de una manera distinta. El egocentrismo no solucionará los problemas del mundo. Y las personas que rompan con el egocentrismo aportarán algo muy importante a la vida y a la felicidad de nuestra sociedad.

Madrid, Trotta, p. 29 y sg. Notar la alusión al clásico tema del "divertissement" de Pascal.

${ }^{18}$ Esto es lo que sugiere S. Ignacio en el célebre Principio y fundamento de los EE, cuando explica la necesidad de la indiferencia [23] y también cuando habla de la reforma de vida y estado [189] Porque piense cada uno que tanto se aprovechará en todas cosas espirituales, cuanto saliere de su propio amor, querer, e interesse.

19 P.H. KolvenBaCH, "Discurso de Monte Cuco". 


\subsection{Una espiritualidad abierta a la realidad ${ }^{20}$}

La espiritualidad que aquí se propone no tiene nada de intimista o autocentrada. Lo primero que hay que hacer para trabajar el espíritu es abrirse a la realidad. Pero hay que vigilar la calidad de esta apertura. Hay una apertura superficial a la realidad: la del turista que la fotografía para poseerla; la del que se conforma con clichés y tópicos en su interpretación; la del que pasa rápidamente de una a otra cosa, incapaz de profundizar en nada. El denominador común de estas actitudes es la "in-quietud", la incapacidad de "parar" la aceleración en la que vivimos habitualmente la vida cotidiana.

La apertura necesaria para trabajar el espíritu intenta tomar como punto de partida la serenidad y la lucidez. La serenidad recupera un ritmo ajustado a lo que la realidad necesita para ser conocida y valorada. La lucidez sabe posar la mirada, también, sobre lo que no es agradable de ver y permite conocer lo que realmente es, no sólo lo que uno desearía que fuera. Porque la apertura aspira a conocer a fondo la realidad: en extensión y en profundidad; es curiosidad en el sentido "serio" de la palabra ${ }^{21}$

Finalmente, la apertura a la realidad necesita de la sensibilidad. Se trata de la capacidad de captar el valor de las cosas y las personas, de dejarse impactar por la realidad de manera que llega a producirnos maravilla y conmoción... La sensibilidad se desarrolla principalmente en cuatro grandes campos: la relación con la naturaleza, la contemplación activa de las obras de arte, la relación profunda con las otras personas y de una manera especial con los que sufren, con los pobres y marginados; es la conciencia aguda del sufrimiento ajeno... La atención activa al entorno y a uno mismo son imprescindibles: la indiferencia, el pasotismo escéptico, el individualismo egocéntrico, la diversión evasiva el cerrar los ojos a la realidad... así como pretender ignorar lo que no se puede encerrar en los propios cuadros mentales, en las propias expectativas, son actitudes que van en dirección contraria a lo que estamos señalando. ${ }^{22}$

Esto es importante en la educación: el P. Kolvenbach decía en la Universidad de Santa. Clara que

Los estudiantes, a lo largo de su formación, tienen que dejar entrar en sus vidas la realidad perturbadora de este mundo de tal manera que aprendan a sentirlo, a pensarlo

${ }^{20}$ Aquí sigo otra vez a M. CORBí, Hacia una espiritualidad laica, cap. VII. p.s 330-341.

${ }^{21}$ Las siguientes citas de CoRBí están tomadas de un artículo anterior: Idees, n 13, Barcelona, 1999, M. CoRBí, y R. RiberA, "Interès, distanciament, silenciament" p.s 109-122.

${ }^{22}$ M. CORBí y R. RiberA, op. cit. p. 112. 
críticamente, a responder a sus sufrimientos y a comprometerse con él de forma constructiva.

\subsection{Una espiritualidad capaz de tomar distancia de la realidad}

Abrirse a la realidad no significa dejarse deslumbrar ni seducir por ella. La espiritualidad que proponemos desarrolla la capacidad de distancia que antes se ha señalado como una característica esencial del espíritu humano. Se trata de dejar que las cosas se nos aparezcan como realmente son, no como nos gustaría que fueran para responder a mis necesidades y deseos. Se trata de lograr la máxima objetividad posible frente al subjetivismo egocéntrico. Se trata de desarrollar el sentido crítico que supone que las explicaciones obvias de las cosas son sometidas a revisión. Pero todo esto no es posible sin una gran dosis de algo sobre lo que los místicos han insistido una y otra vez: el desapego respecto de los propios afectos y también sobre nuestra manera cotidiana de interpretar la realidad.

El apego a sentimientos y opiniones es un gran mecanismo de defensa contra la inseguridad que nos produce un mundo cambiante que nos supera continuamente. Pero el apego nos impide cambiar la manera de entender y valorar las cosas cuando esto hace falta. El desapego no es una actitud ascética de desprecio del mundo. Al contrario, como señala Corbí:

Sin distanciamiento, sin desapego y sin desidentificación de la situación y de mi mismo, no podré hacer justicia a la realidad que se me presenta. Las características de este segundo rasgo de la espiritualidad son hijas del amor y la pasión por la verdad y la realidad..$^{23}$

\subsection{Una espiritualidad capaz de descubrir y captar el misterio de la realidad}

El rasgo característico de la espiritualidad que hasta ahora se ha dibujado ha sido la salida de si mismo: la apertura a la realidad, la distancia y el desapego se pueden definir como procesos de des-centramiento: la realidad importante deja de ser mi propio ego que busca la supervivencia y su propio bienestar a todos los niveles y pasa a ser la realidad en si misma: tanto la exterior a mi como yo mismo, pues yo formo parte de la realidad englobante. Este "silencio del ego" como algunos lo han definido, es un proceso sin fin en la vida humana. Los grandes santos y los grandes hombres y mujeres de la humanidad lo han recorrido en mayor medida que las personas que nos consideramos "corrientes", no excepcionales.

${ }^{23}$ Ibídem. El subrayado es mío. 
Lo interesante es notar que este vaciamiento, que suena muy austero, ha sido siempre descrito a la vez como inmensamente gratificante. Los santos y santas que se han adentrado en este camino han descubierto que podían ver y experimentar el conjunto de la vida y de la realidad "de otra manera" y que la realidad se les aparecía ciertamente misteriosa, con-movedora en el sentido etimológico de la palabra (que mueve con, que despierta sintonía profunda), a veces terrible, pero en definitiva digna de ser "amada y servida" 24 .

Los cristianos decimos que "el Espíritu de Dios llena el mundo" y lo transfigura. Jesús, que estaba lleno de este Espíritu, anunciaba esta buena nueva a los pobres: es decir a los que son víctimas de esta manera egocéntrica de ver y vivir la realidad que lleva al autocentramiento, a la posesividad y al dominio de los otros, y que tiene como consecuencia la pobreza, la exclusión social y opresión del débil. Jesús, liberado de todo ego-centrismo captaba la realidad "como es en si misma", "a los ojos de Dios": como proximidad y amor de un Dios que creó el mundo "y vio que era bueno"; que "hace salir el sol sobre buenos y malos", que "cuenta hasta los cabellos de la cabeza" de cada persona ${ }^{25}$. Un Dios al que se accede en la medida en que nos dejamos fascinar por los destellos, las rendijas de este Espíritu que llena el mundo, les seguimos la pista en el discernimiento y avanzamos en el camino del seguimiento de Jesús que es el camino del amor des-apegado, el camino, correlativamente, del "silencio del ego".

\section{Consecuencias para una pedagogía del espíritu}

\section{I.Trabajar el espíritu humano}

Este trabajo del espíritu, tal como se ha descrito, no se trabaja en una interioridad desconectada del mundo sino en el mundo mismo, El esquema siguiente pretende sugerir esta concepción de la realidad: el espíritu humano esta abierto al Espíritu de Dios que lo impregna todo y se puede descubrir en todo.

\footnotetext{
${ }^{24}$ Véase lo que dice de si mismo S. Ignacio al describir la "iluminación" del Cardoner: Autobiografía, $n^{\circ} 30$ : "le parecían todas las cosas nuevas... recibió una gran claridad en el entendimiento". Ya se ha citado el texto sobre el amar y servir.

25 José Antonio Pagola describe de manera impactante como Jesús anunciaba el reino de este Dios al que llamaba "Abba". Ver J. A. PAGOLA (2007) Jesús. Aproximación histórica, Madrid, PPC.
} 
Figura 2

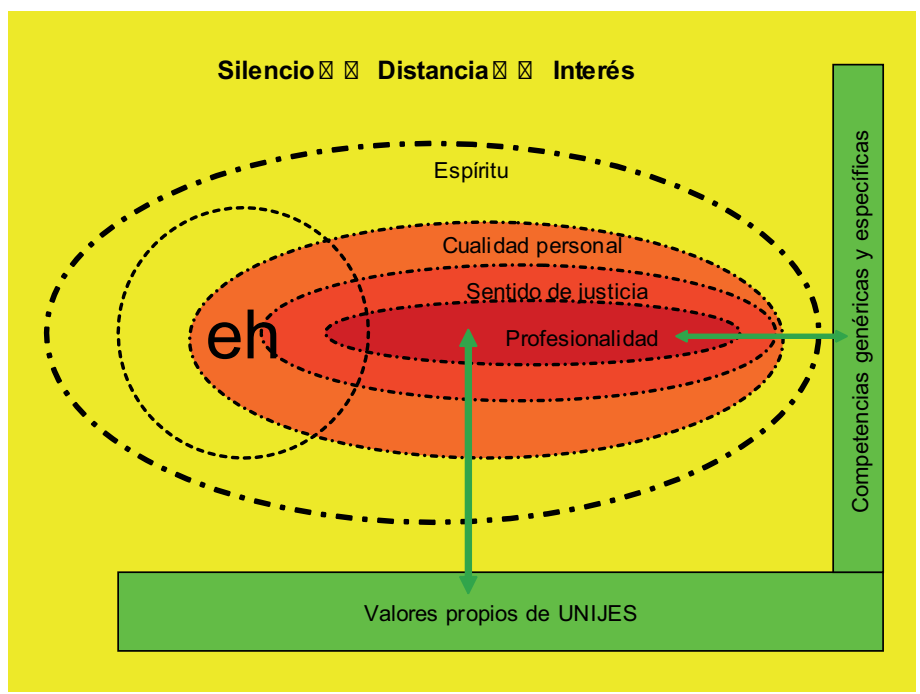

El esquema pretende visualizar otra perspectiva sobre las relaciones entre los valores UNIJES, el espíritu humano y el Espíritu de Dios. El esquema quiere sugerir que cada valor "engloba" o abarca los anteriores. Por ello mismo, al trabajar seriamente cada uno de ellos se trabaja el conjunto, y por tanto también la preparación de una posible opción madura por la fides. Trabajar el espíritu humano tiene repercusiones en todos los valores. Las elipses tienen bordes discontinuos para expresar su "porosidad" a la presencia omniabarcante del Espíritu de Dios. El esquema así explicado va orientado al creyente. Pero el no creyente puede aceptar muy bien la "porosidad" de la utilitas, la iustitia y la humanitas al espíritu humano y la legitimidad de una posible, no necesaria apertura a la fides.

Lo importante es descubrir qué tipo de trabajo sobre la utilitas, la iustitia y la humanitas cultivan el espíritu humano de manera que éste se abra a la realidad descubriéndola, sea como realidad impregnada del Espíritu de Dios lopción creyente), sea como realidad que merece fidelidad a lo verdadero, fidelidad al amor pero también rechazo a un dios garante a la vez de la verdad y del amor (opción no creyente) ${ }^{26}$.

\footnotetext{
${ }^{26}$ A. Compte-SPOnVILLe, op. cit. p. 210.
} 
¿Cómo trabajar el espíritu humano? Se ha dicho ya antes y sólo queda recapitular y acentuar lo más relevante desde el punto de vista de la formación humana integral.

- Alimentar la sensibilidad profunda parece el punto de partida indispensable. Sin ella no hay apertura inicial a la realidad. En el aula, la sensibilidad al conocimiento y sobre todo al sentido humano de este conocimiento es esencial. Por desgracia, un concepto limitado de la profesionalidad como saber puramente técnico al servicio de finalidades que se dan por supuestas (las que marca el mercado) oscurece el sentido humano del conocimiento y de la profesión. Recuperarlo es un importante "trabajo del espíritu".

- Provocar la "reflexividad", la distancia. La cultura postmoderna capta bien la importancia de la sensibilidad pero puede quedar prisionero de ella. Sin "reflexividad" y sin distancia no puede haber gratuidad: el amor queda prisionero del deseo de que la realidad (la situación social, la persona del otro, la realidad de mi mismo, el misterio de la vida) sea como yo lo deseo. La distancia permite amar con lucidez y realismo. Permite amar y vivir el amor en la austeridad del servicio.

En el aula la "reflexividad" se puede trabajar de múltiples maneras, haciendo ver la importancia de reconocer la realidad intelectual o práctica tal como realmente es. Pero es importante hacer sentir que la realidad puede ser cambiada y de hecho lo ha sido: no por unos sueños de omnipotencia sino por la humilde acción lúcida, informada y orientada por valores (positivos o negativos para la humanidad). Como dice M. Castells

No hay un mal eterno en la naturaleza humana. No hay nada que no pueda ser cambiado por la acción social consciente e intencionada, provista de información y apoyada por la legitimidad. Si las personas está informadas, son activas y se comunican a lo largo del mundo; si la empresa asume su responsabilidad social; si los medios de comunicación se convierten en mensajeros en lugar de ser el mensaje; si los actores políticos reaccionan contra el cinismo y restauran la fe en la democracia; si la cultura se reconstruye desde la experiencia; si la humanidad siente la solidaridad de la especie en todo el planeta; si afirmamos la solidaridad intergeneracional viviendo en armonía con la naturaleza; si emprendemos la exploración de nuestro yo interior, haciendo la paz con nosotros mismos. Si todo esto se hace posible por nuestra decisión compartida, informada y consciente, mientras aún hay tiempo, quizá entonces, por fin, seremos capaces de vivir y dejar vivir, de amar y ser amados 27 .

${ }^{27}$ M. CASTeLls, La era de la información, Madrid, Alianza Editorial. Vol. III, p. 394. 
- Tal vez lo más difícil en el mundo actual sea provocar y trabajar la sorpresa, la maravilla y sobre todo el silencio, que es la antesala de la captación de la existencia como misterio. Ojalá se pudiera provocar con cierta frecuencia la maravilla del "descubrimiento" ligado al progreso en el conocimiento. Pero tal vez el campo más adecuado para ello sea la profundización de las relaciones personales que se inician en los trabajos de equipo y en los voluntariados: como decía Camus, en el ser humano siempre hay más elementos que conducen a la admiración que al desprecio. En las relaciones personales se descubre el valor incondicionado de la persona (su dignidad) que brilla de una manera especial en el pobre y humillado. Guiados por esta confianza pensamos que el encuentro humano es una de las grandes vías de acceso al misterio de la vida y al cultivo del espíritu.

- Estas tres dimensiones de la espiritualidad no están separadas. Pensamos más bien que se relacionan en un movimiento circular en el que cada elemento refuerza y orienta el desarrollo de los otros elementos. Por esto la pedagogía del espíritu ha de ser siempre consciente de todas las dimensiones aunque no pueda explicitarlas simultáneamente.

\section{Figura 3}

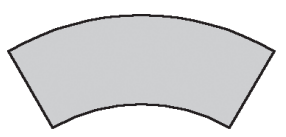

Sensibilidad Interés

Distancia
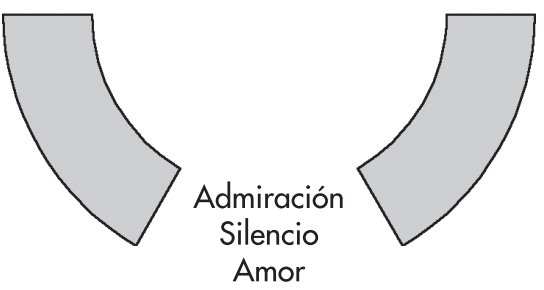

\subsection{Pedagogía en el aula}

Trabajar el espíritu puede hacerse en el aula. Es más, es necesario hacerlo para no limitar las competencias que debe adquirir el alumno a meras capacidades para el mercado (aunque tales capacidades sean también necesarias). Trabajar 
las competencias en la perspectiva de los valores de UNIJES significa quitarles la ambigüedad que tienen al trabajarlas solamente en la perspectiva de una utilitas reducida al éxito profesional en el mercado.

Veamos un ejemplo, ilustrado en el cuadro siguiente:

\section{Cuadro I}

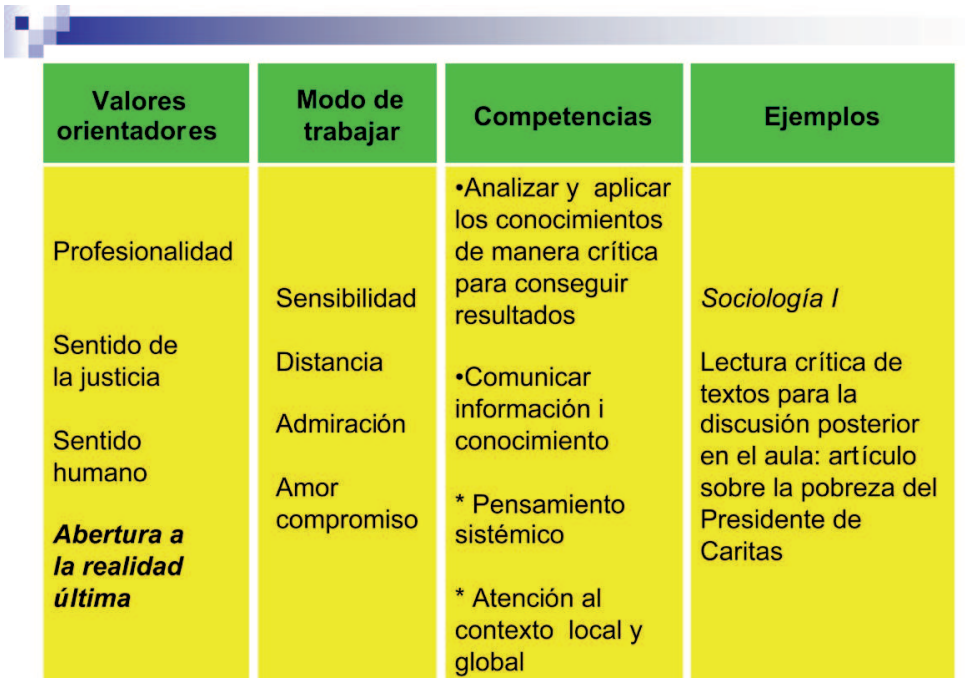

En la asignatura de Sociología I del grado en Administración y Dirección de Empresas se estudia la pobreza y se utiliza como material un artículo del director general de Caritas Española en El País ${ }^{28}$.

Las competencias EEES orientan hacia un trabajo conceptual necesario para que los valores UNIJES no queden luego en pura moralina emocional: hay que trabajar conceptos como el de definición de pobreza, la pobreza relativa o absoluta, el umbral de pobreza y el debate actual sobre la salida de la pobreza como un desarrollo de capacidades. Habrá que exigir que los alumnos lleguen a saber formularse con precisión y que integren lo que aprenden ahora con otros elementos ya estudiados o que se estudiarán más tarde: desarrollo, Estado del bienestar, etc.

${ }^{28}$ S. Agea (2006) "Lo que no queremos ver", El País 22 de enero. 
Desde el punto de vista de los valores UNIJES, es importante que los alumnos integren la conexión de la pobreza con el modelo de desarrollo de una sociedad concreta y también con el modelo de empresa dominante en tal sociedad. De este modo la pobreza no sólo será percibida como una responsabilidad gubernamental sino también como una responsabilidad ciudadana y profesional (iustitia y utilitas). En algún momento hay que llegar a formular que si la pobreza es inadmisible es porque toda persona tiene un valor incuestionable, su dignidad y que la pobreza, atenta a esta dignidad. En algún momento puede debatirse las motivaciones, laicas o religiosas que animan a muchos a luchar contra la pobreza.

El paso de la columna de las competencias EEES a los valores de UNIJES viene mediado por las maneras de trabajar el espíritu que evitan un trabajo puramente moralista. La distancia viene dada por el trabajo conceptual antes mencionado que habrá que compensar con estrategias para "acercar" el problema y hacer sentir su importancia. Las narraciones, los fragmentos de películas o de documentales pueden ayudar a ver que los afectados son personas semejantes a cada uno de nosotros. Lo importante es educar la sensibilidad que hace captar la dignidad en las personas que son víctimas de situaciones injustas o que luchan en circunstancias adversas por salir de la pobreza.

Como se decía antes, lo más difícil parece ser provocar la admiración que puede llevar al silencio. Es decir: se trata de que en esta situación el alumno no reaccione con los tópicos que su experiencia le proporciona, que le evitan pensar y que le quitan responsabilidad. Se trata de provocar el desapego respecto a las respuestas socialmente "normales" y de invitar a reaccionar con libertad de espíritu a la interpelación profesional, cívica y humana que la pobreza plantea.

Trabajar todos estos aspectos es trabajar un desarrollo del espíritu que hace posible una maduración de la fides en el caso de que el alumno sea creyente y una opción más lúcida por una ética laica en caso contrario. Lo importante, otra vez, es hacer caer en la cuenta de la conexión existente entre campos de la vida humana que el alumno vive normalmente como separados.

El ejemplo propuesto muestra las posibilidades y también las dificultades de lo que pretendemos. La asignatura y el tema propuesto como ejemplo tienen una conexión bastante evidente con los valores de UNIJES. El trabajo será ciertamente más mediatizado y difícil en Contabilidad, Finanzas y otras asignaturas especialmente técnicas. Sin embargo con imaginación y constancia se puede trabajar en esta línea. Un profesor de Sistemas de Información (una asignatura que todos diríamos eminentemente "técnica") me ha explicado recientemente que se ha propuesto 
elegir casos en los que aparezcan valores y que den a lugar a la discusión de estos valores, y de hecho, lo ha conseguido.

También es ciertamente difícil trabajar todos estos aspectos porque esto supone tiempoy recursos (materiales, trabajo en pequeños grupos, etc.). Desde esta perspectiva, la exigencia del nuevo modelo pedagógico de establecer con cierta precisión "objetivos de aprendizaje", competencias, procedimientos para el aprendizaje, etc. puede permitir diseñar estrategias de trabajo progresivo de estos valores: no se trata de trabajarlo todo en cada punto del programa... Por ello el enfoque que proponemos es el de un trabajo a largo término y que debería ser en buena parte un trabajo en equipo del conjunto de profesores, o al menos de un pequeño grupo con voluntad decidida de progresar en esta dirección, contando con el apoyo claro de la institución académica.

\section{Conclusión}

El contenido de esta ponencia no pretende en absoluto ser definitivo. Sin duda se trata de una indagación que cada vez parece más necesaria y en la que confluimos muchas personas desde perspectivas muy diferentes, pero que está todavía en una fase inicial. Por esto quisiera terminar con un texto de Dag Hammarskiöld en el que me encuentro reflejado en profundidad y que en cierto modo se podría proponer como clave de lectura de todo lo que he intentado decir:

Dios no muere el día en que dejamos de creer en una divinidad personal. Pero nosotros morimos el día en que nuestras vidas dejan de estar iluminadas por el permanente resplandor, renovado cada día, de un misterio el origen del cual escapa a la razón ${ }^{29}$.

29 D. HAMMARSKJöLD (1999) "Marcas en el camino" en ¡Te conocimos, Señor! Madrid, Biblioteca de Autores Cristianos. Con textos de Manuel García Morente, Dag Hammarskjöld y André Frossard. Edición preparada por T. H. Martín con introducciones de J. Martín Velasco, p. 146. 